\title{
A combined role of calcium channel blockers and angiotensin receptor blockers in stroke prevention
}

This article was published in the following Dove Press journal:

Vascular Health and Risk Management

20 July 2009

Number of times this article has been viewed

\section{Ji-Guang Wang}

Centre for Epidemiological Studies and Clinical Trials, Ruijin Hospital, Shanghai Jiaotong University School of Medicine, Shanghai, China
Correspondence: Ji-Guang Wang Shanghai Institute of Hypertension, Ruijin 2nd Road 197, Shanghai 200025, China

Tel +86-2 I-64370045 Ext 6 I09। I

Fax +86-2I-64662193

Email jiguangw@gmail.com

\begin{abstract}
Stroke is a leading cause of death and disability worldwide. The importance of lowering blood pressure for reducing the risk of stroke is well established. However, not all the benefits of antihypertensive treatments in stroke can be accounted for by reductions in BP and there may be differences between antihypertensive classes as to which provides optimal protection. Dihydropyridine calcium channel blockers, such as amlodipine, and angiotensin receptor blockers, such as valsartan, represent the two antihypertensive drug classes with the strongest supportive data for the prevention of stroke. Therefore, when combination therapy is required, a combination of these two antihypertensive classes represents a logical approach.
\end{abstract}

Keywords: stroke, angiotensin, calcium channel, cerebrovascular, hypertension, blood pressure

\section{Introduction}

Stroke is a leading cause of death and disability worldwide. ${ }^{1}$ It has been estimated that 15 million people worldwide suffer a stroke each year and one-third of these individuals will die. ${ }^{2}$ Moreover, one-third of these stroke victims will be left permanently disabled, profoundly affecting their quality of life and placing a large burden on their families, communities and society. ${ }^{2}$ The total incidence of stroke is expected to increase considerably over the next two decades. ${ }^{1}$ In the European Union, for example, the World Health Organization-estimated number of stroke events is expected to increase from 1.1 million in 2000 to 1.5 million by $2025 .{ }^{3}$ In other, less developed regions of the world, stroke is reaching pandemic proportions as a result of rapid urbanization and industrialization. ${ }^{4}$

\section{Risk factors for stroke and the importance of blood pressure lowering}

Risk factors for stroke are classified according to whether they are modifiable or not. Nonmodifiable risk factors include old age, male gender, Asian and Black ethnicities, and strong family history. Among the well documented modifiable risk factors for stroke are: hypertension, cigarette smoking, diabetes, dyslipidemia, obesity, atrial fibrillation (AF), carotid artery stenosis, and a previous stroke, transient ischemic attack (TIA) or heart attack. ${ }^{5}$ In addition, left ventricular hypertrophy (LVH) and abnormal left ventricular geometry have been shown to be associated with increased risk of stroke in a multi-ethnic population. ${ }^{6}$

A prior stroke or TIA places patients at very high risk of a recurrent cerebrovascular event. ${ }^{7}$ Indeed, in a population-based study of early risk of stroke after a TIA or 
minor stroke, the estimated risk of recurrence at 3 months post event was $17.3 \%$ and $18.5 \%$, respectively. ${ }^{8}$ In a Chinese patient population with ischemic stroke who were registered in the Nanjing Stroke Registry Program, a first-year recurrence rate of $11.2 \%$ was reported. This is of interest because data on stroke occurrence and recurrence are very limited in China ${ }^{9}$ and much of Asia. ${ }^{10}$ Given the global burden of stroke, effective therapeutic interventions aimed at primary and secondary prevention are needed.

Of the modifiable risk factors for stroke, hypertension serves as the most prevalent and powerful of risks, ${ }^{11}$ regardless of geographic location and ethnicity. Approximately 54\% of strokes worldwide can be attributed to elevated blood pressure (BP). ${ }^{12}$ Such is the association that people with hypertension are 3 to 4 times more likely to suffer a stroke than those without hypertension. ${ }^{13}$ The relationship between $\mathrm{BP}$ and risk of first stroke is direct, continuous and independent, with the risk increasing continuously above a BP of $115 / 75 \mathrm{mmHg} .{ }^{11}$ Hypertension also increases the risk of stroke recurrence and it has been shown that approximately $25 \%$ to $30 \%$ of patients recovering from a stroke have raised BP at the time of discharge from hospital. ${ }^{14}$

There is strong and consistent evidence that lowering elevated BP is an important therapeutic target in the primary and secondary prevention of stroke, regardless of age, gender or ethnicity (Asian or White). ${ }^{15}$ A meta-analysis of nine randomized comparative trials found that a reduction in systolic blood pressure (SBP) of just 1 to $3 \mathrm{mmHg}$ led to a reduction in risk of stroke of $20 \%$ to $30 \% .{ }^{16}$ Moreover, in age-specific analyses from two cohort study overviews (the Prospective Studies Collaboration and the Asia Pacific Cohort Studies Collaboration), ${ }^{17}$ a $10 \mathrm{mmHg}$ reduction in SBP was associated with a $35 \%$ reduction in the risk of stroke in subjects aged 60 to 69 years (Table 1). ${ }^{18}$ Similar benefits have also been shown for stroke survivors. In a meta-analysis including 6752 patients with a previous history of cerebrovascular disease (stroke or TIA), antihypertensive therapy resulted in a $28 \%$ reduction in risk for stroke recurrence. ${ }^{19}$ Antihypertensive treatment that effectively reduces $\mathrm{BP}$ to target levels may therefore be one of the most important approaches for reducing the risk of stroke. Indeed, the importance of treatment has been demonstrated in a study where early discontinuation with antihypertensive therapy was associated with a $28 \%$ increase in the risk of stroke..$^{20}$

This review will examine the evidence available for the use of calcium channel blockers (CCBs) and renin angiotensin system (RAS) blockers - with focus on angiotensin receptor blockers (ARBs) - in the primary and secondary prevention of stroke, and explore whether there is potential in this regard for dual-mechanism therapy with a $\mathrm{CCB} / \mathrm{ARB}$.

\section{Antihypertensive therapy in the primary and secondary prevention of stroke \\ What evidence is available with CCBs?}

Numerous studies have compared the effects of CCBs with placebo or an active treatment for preventing cerebrovascular events (Table 2). Two placebo controlled trials, the Prospective Randomized Evaluation of the Vascular Effects of Norvasc Trial (PREVENT) and Systolic Hypertension in Europe (Syst-Eur) study have assessed the effects of CCBs compared with placebo for reducing the risk of stroke. ${ }^{21-23}$ A meta-analysis of these two trials provided clear evidence of a reduction in stroke risk with CCBs vs placebo of $39 \%{ }^{18}$ The Systolic Hypertension in China (Syst-China) study has also confirmed the benefits of the dihydropyridine CCB, nitrendipine, for improving prognosis in Chinese patients. Indeed, nitrendipine-based treatment reduced the incidence

Table I Reductions in the risk of stroke related to systolic blood pressure (SBP) predicted from cohort studies and observed in clinical trials

\begin{tabular}{|c|c|c|c|}
\hline & \multicolumn{2}{|c|}{$\begin{array}{l}\text { Predicted effects on stroke } \\
\text { of lowering SBP } 10 \mathrm{mmHg}\end{array}$} & \multirow{2}{*}{$\begin{array}{l}\text { Observed effects on stroke with } \\
\text { a reduction in SBP of } 10 \mathrm{mmHg} \\
\text { Estimated mean age at event }\end{array}$} \\
\hline & \multicolumn{2}{|c|}{ Mean age at event } & \\
\hline & $60-69$ years & $70-79$ years & Approximately 73 years \\
\hline Prospective Studies Collaboration (2002) & $34 \%$ & $29 \%$ & $31 \%$ \\
\hline Asia Pacific Cohort Studies Collaboration (2003) & $36 \%$ & $25 \%$ & \\
\hline
\end{tabular}

Reproduced with permission from Lawes CM, Bennett DA, Feigin VL, Rodgers A. Blood pressure and stroke: an overview of published reviews. Stroke. 2004;35(4): 1024-1033.18 Copyright (c) 2004 Lippincott Williams \& Wilkins.

aRelative risk reduction in stroke from cohort studies with a $10 \mathrm{mmHg}$ lower SBP, by age at event.

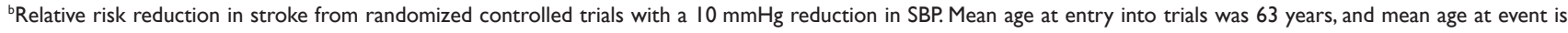
likely estimated to be a decade later (ie, 73 years). 
of fatal and nonfatal stroke by $38 \%$ (hazard ratio [HR] 0.62 [95\% confidence interval (CI) 0.42-0.91]; $P<0.05) .{ }^{24}$ In addition, in the ACTION (A Coronary disease Trial Investigating Outcome with Nifedipine GITS) trial, a CCB reduced the risk of any stroke or TIA by $30 \%$ compared with placebo in patients with hypertension and stable angina. ${ }^{25}$ Following ischemic stroke, CCB treatment has been associated with a reduction in mortality (odds ratio [OR] 0.38 [0.17-0.88] vs no CCB treatment) and improvements in the stroke impact scale-16. ${ }^{26}$

In addition to their benefits compared with placebo, CCBs have also been shown to provide better protection against fatal and nonfatal stroke than older drugs, such as $\beta$-blockers and diuretics. ${ }^{27,28}$ In addition, CCBs have been shown to provide benefit over angiotensin-converting enzyme inhibitors (ACEIs) (11\% relative risk [RR] reduction) in a meta-analysis of 4 trials (the Appropriate Blood Pressure Control in Diabetes [ABCD], the Antihypertensive and Lipid-Lowering Treatment to Prevent Heart Attack Trial [ALLHAT], the Fosinopril Versus Amlodipine Cardiovascular Events Randomized Trial [FACET] and the Swedish Trial in Old Patients with Hypertension [STOP-2].${ }^{18}$ A meta-regression analysis has confirmed that $\mathrm{CCBs}$ are superior to ACEIs for the prevention of stroke $(P=0.042) .^{29}$

\section{Amlodipine}

In the BP-lowering arm of the Anglo-Scandinavian Cardiac Outcomes Trial (ASCOT), amlodipine-based treatment reduced fatal and nonfatal stroke by $23 \%$ (HR 0.77 [0.66-0.89]; $P<0.0003$ ) compared with atenololbased treatment in a range of high cardiovascular (CV) risk patients ( $11 \%$ with a previous stroke or TIA) with uncontrolled BP (SBP $\geq 160 \mathrm{mmHg}$ and/or diastolic blood pressure $[\mathrm{DBP}] \geq 100 \mathrm{mmHg}$ BP not on antihypertensive treatment or $\mathrm{SBP} \geq 140 \mathrm{mmHg}$ and/or $\mathrm{DBP} \geq 90 \mathrm{mmHg}$; $\mathrm{n}=19342) .{ }^{30}$ On average, BP levels were lower throughout the trial in patients allocated to amlodipine-based treatment compared with atenolol-based treatment (average difference 2.7/1.9 mmHg). Although BP was the largest contributor to stroke events, peripheral BP measurements could not fully account for the treatment differences in stroke. ${ }^{31}$

The Comparison of AMlodipine vs Enalapril to Limit Occurrences of Thrombosis (CAMELOT) study compared amlodipine with enalapril or placebo in 1991 patients with angiographically documented coronary artery disease and DBP $<100 \mathrm{mmHg}$. Amlodipine reduced the risk of stroke or TIA by $50 \%$ compared with placebo (HR 0.50 [0.19-1.32]) and $24 \%$ compared with enalapril (HR 0.76 [0.26-2.20]), although these reductions did not achieve statistical significance $(P=0.15$ and $P=0.61$, respectively), possibly due to the small numbers of events. ${ }^{32}$

ALLHAT compared three different antihypertensive regimens (amlodipine, chlorthalidone, and lisinopril) in 33357 patients with stage 1 or 2 hypertension and at least one other risk factor for coronary heart disease. ${ }^{33}$ Almost one quarter $(23 \%)$ of patients had a previous history of stroke or myocardial infarction (MI) at baseline. Stroke was assessed as a secondary endpoint and there were significantly more strokes for lisinopril compared with amlodipine (RR 1.23 [1.08-1.41]; $P<0.003) .{ }^{34}$ On average, follow-up BP was $1.5 / 1.1 \mathrm{mmHg}$ higher in patients treated with lisinopril compared with amlodipine. ${ }^{34}$ However, there was no significant difference in stroke incidence between amlodipine and chlorthalidone (RR 0.93 [0.82-1.06]; $P=0.28$ ) in this study. ${ }^{33}$

An analysis of six actively controlled trials involving an amlodipine treatment group (including the three trials described above plus the Candesartan Antihypertensive Survival Evaluation in Japan [CASE-J] trial, the Valsartan Antihypertensive Long-term Use Evaluation [VALUE] and the Irbesartan Diabetic Nephropathy Trial [IDNT]) showed that amlodipine provided more protection against stroke than other antihypertensive agents (OR 81 [95\% CI 0.75-0.87]; $P<0.0001) .{ }^{35}$ Moreover, the risk of stroke with amlodipine was statistically less when compared with non-ARB antihypertensive drugs (OR 0.79 [95\% CI 0.72-0.87]; $P<0.0001$ ) and ARB therapies separately (OR $0.84[95 \%$ CI 0.73-0.97]; $P=0.02$ ).

\section{What evidence is available with ARBs?}

\section{The RAS}

The RAS has been linked to the development and progression of cerebrovascular disease in patients with hypertension. ${ }^{36,37}$ Indeed, angiotensin II is thought to induce cerebrovascular hypertrophy and remodeling, inhibit endothelium-dependent relaxation and disrupt the blood-brain barrier. ${ }^{36}$ Therefore, it might be assumed that RAS blockade would provide cerebroprotection. However, studies with ACEIs have produced mixed results (Table 2).

In the Heart Outcomes Prevention Evaluation (HOPE) study ramipril reduced all stroke by $32 \%$ (RR 0.68 [0.56-0.84]) and fatal stroke by $61 \%$ (RR 0.39 [0.22-0.67]) compared with placebo in a study of 9297 patients with high CV risk ( $\sim 11 \%$ had a prior history of stroke). ${ }^{38,39}$ In the Perindopril Protection Against Recurrent Stroke Study 
WhI

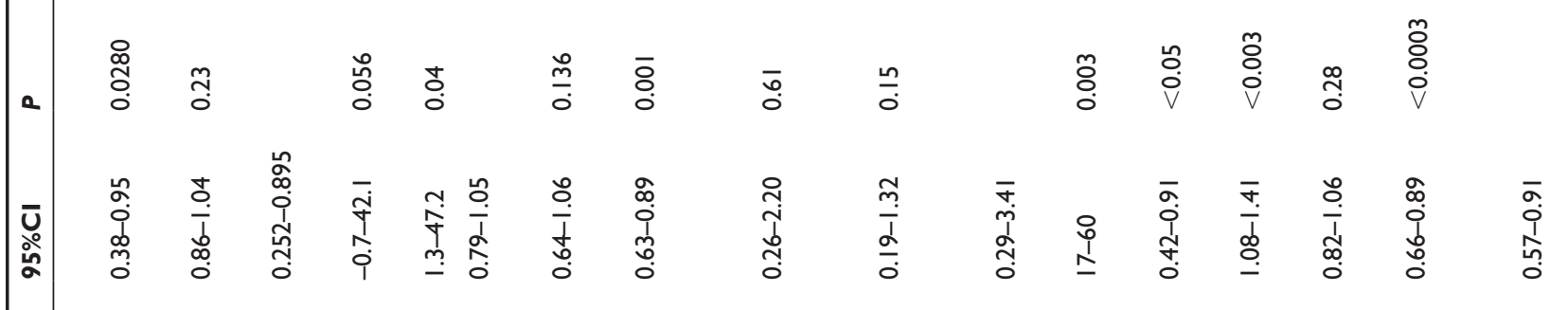

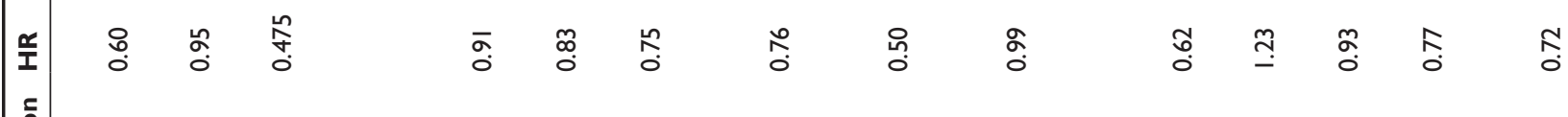

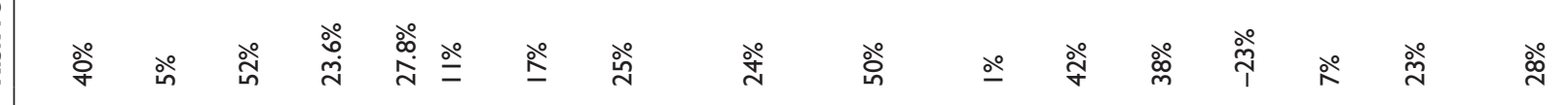

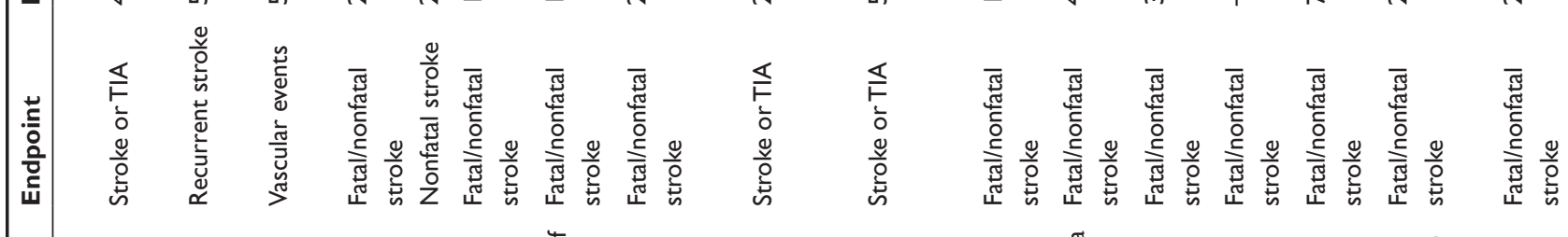

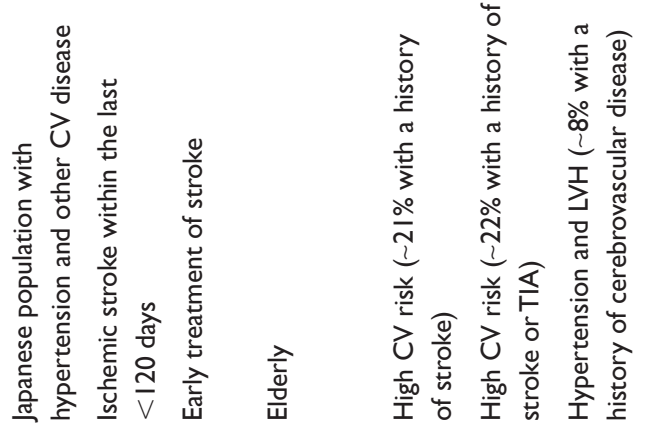

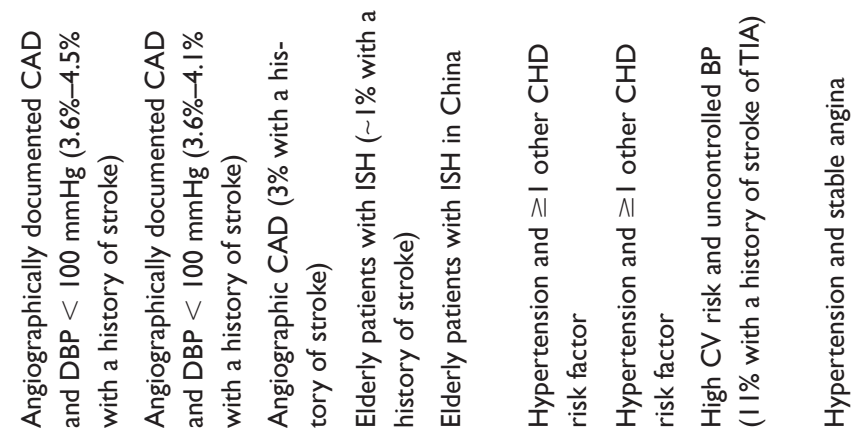

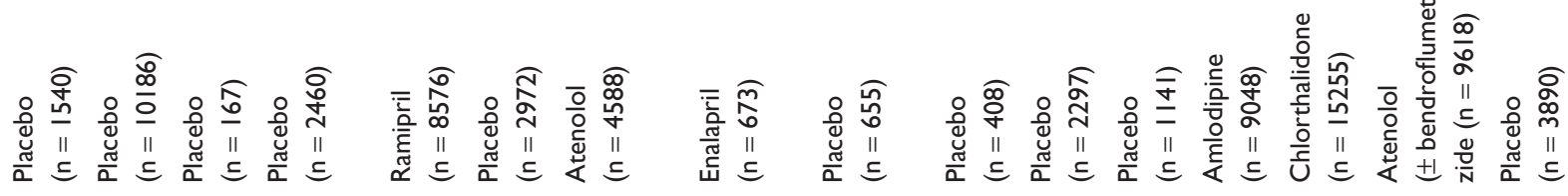

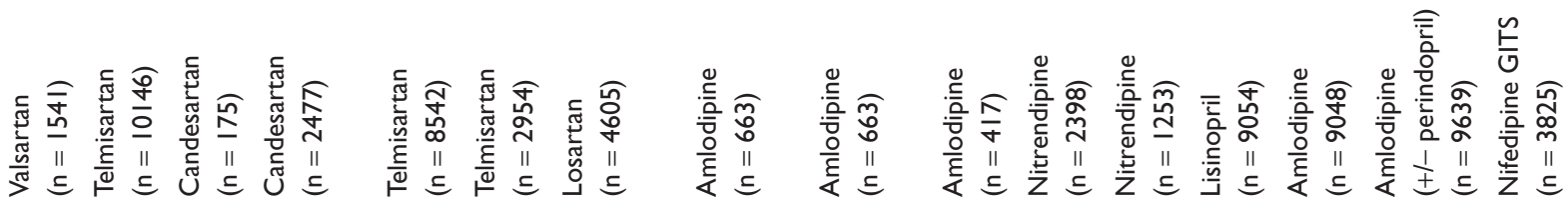

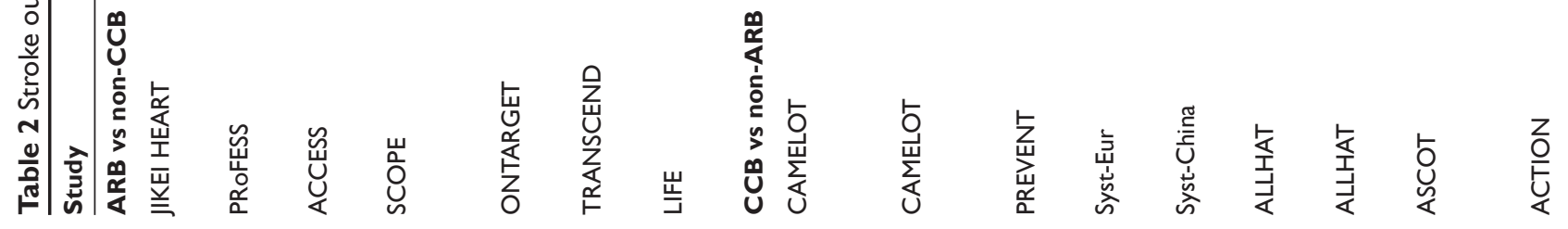




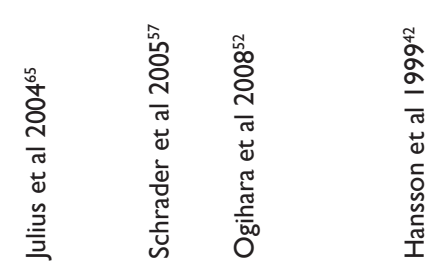

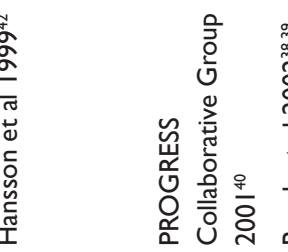

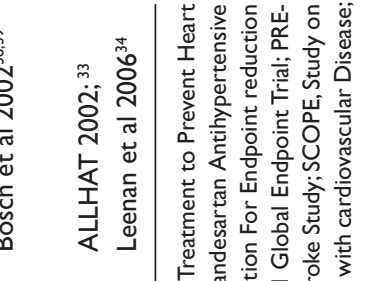

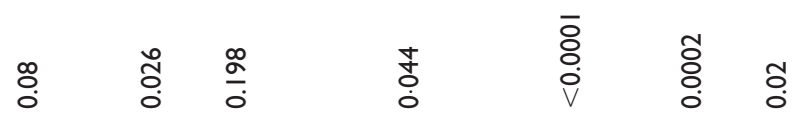

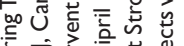

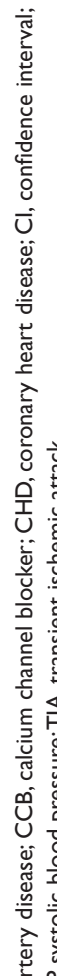

ํำ ㅇํํ @

ॐें

ฌั ㅇํำ

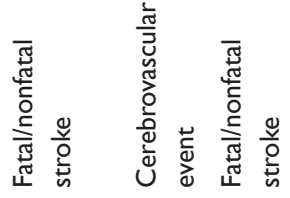

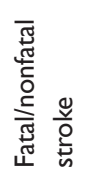

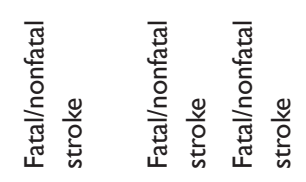

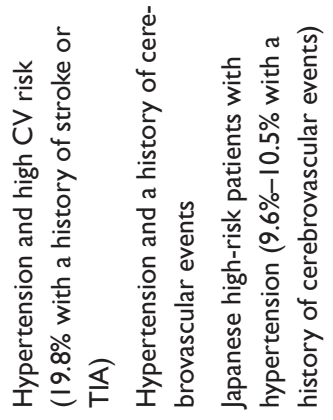

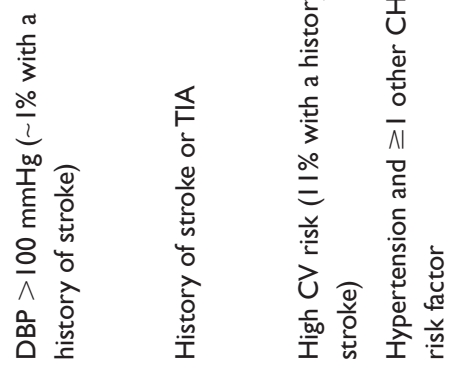

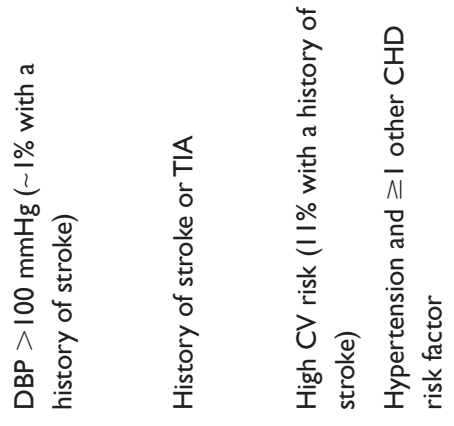

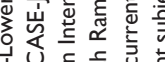

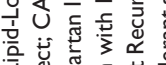

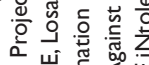

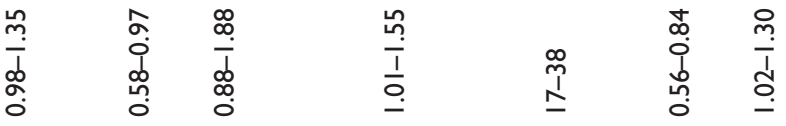

드을

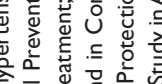

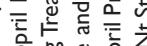

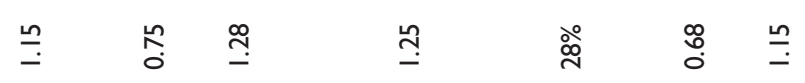

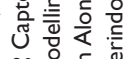

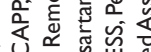

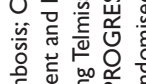

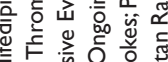

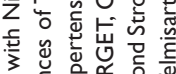

年

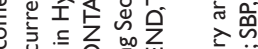

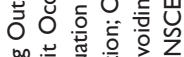

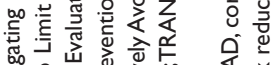

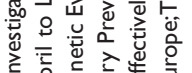

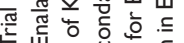

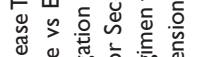

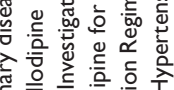

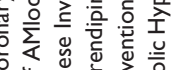

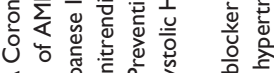

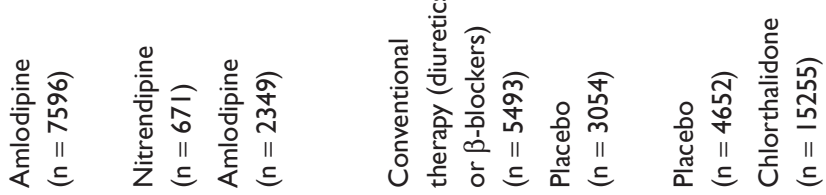

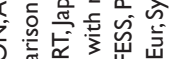

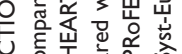

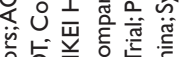

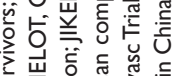

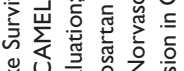

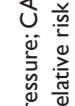

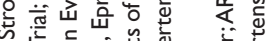

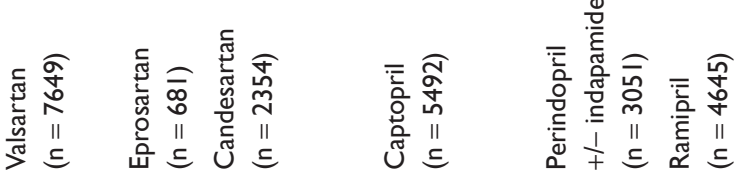

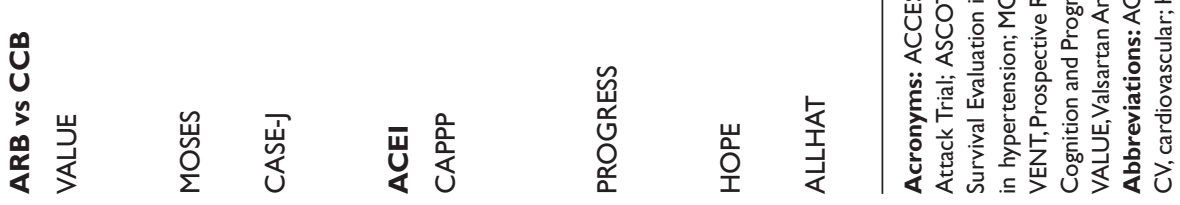


(PROGRESS), active treatment with perindopril monotherapy or perindopril plus a diuretic (indapamide) reduced stroke by $28 \%$ in 6105 patients with a history of stroke or TIA. ${ }^{40}$ However, in PROGRESS, monotherapy with perindopril had little beneficial effect on stroke when compared with placebo, despite a reduction in $\mathrm{BP}$ of $5 / 3 \mathrm{mmHg} .{ }^{40}$ This observation is consistent with a meta-analysis of three smaller trials (Survival And Ventricular Enlargement [SAVE], Acute Infarction Ramipril Efficacy [AIRE] and TRAndolapril Cardiac Evaluation [TRACE]) which did not observe a beneficial effect of ACEIs on stroke compared with placebo (OR 1.10 [0.84-1.43]; $P=0.48$ ) in patients with heart failure (HF) or left ventricular dysfunction. ${ }^{41}$

In studies with an active comparator, data supporting the use of ACEIs are even less convincing. In the Captopril Prevention Project (CAPPP), fatal/nonfatal stroke was found to be 1.25 times more frequent in patients randomized to captopril vs conventional therapy with diuretics, $\beta$-blockers or both, ${ }^{42}$ although a subanalysis found no difference in stroke between study groups in patients with diabetes. ${ }^{43}$ In ALLHAT, lisinopril was less effective in preventing stroke vs chlorthalidone (RR 1.15 [1.02-1.30]; $P=0.02$ ), ${ }^{33}$ although interpreting these findings is confounded by the different BPs achieved.

It has subsequently been suggested that angiotensin II might have a protective effect on stroke. ${ }^{44-46}$ In an analysis of 26 prospective randomized trials during which 7108 strokes occurred in 206,632 patients without HF, Boutitie et al noted that differences in BP do not totally account for differences in stroke risk and that the relative risk of stroke was $17 \%$ greater with agents that potentially decrease angiotensin II levels ( $\beta$-blockers and ACEIs) compared with those that increase angiotensin II levels (thiazide diuretics, dihydropyridine CCBs and ARBs). ${ }^{44}$ It was hypothesized that increased angiotensin II may act on angiotensin type 2 (AT2) receptors and mediate protective effects such as improving collateral circulation and neuronal resistance to anoxia. ${ }^{44}$ However, mechanistic data to support such an effect in the cerebral circulation in humans are lacking and data from animal models should be interpreted with caution as the presence and role of receptors can differ from that in humans.

\section{Stroke protection with ARBs}

According to the hypothesis proposed by Boutitie et al ARBs should help protect against stroke as, in addition to lowering BP, they inhibit the negative effects of angiotensin type I (AT1) receptors in the cerebral circulation, but allow angiotensin to mediate potentially stroke-protective effects through the AT2 receptor. Observations from large clinical trials would support this suggestion.

In the Losartan Intervention For Endpoint reduction in hypertension (LIFE) study, losartan substantially reduced the rate of fatal and nonfatal stroke by $25 \%$ vs atenolol (HR 0.75 [0.63-0.89]; $P=0.001)$ in 9193 patients with hypertension and $\mathrm{LVH}^{47} \mathrm{~A}$ small $(1.1 \mathrm{mmHg})$ but significant difference in the reduction in systolic BP $(P=0.017)$ was observed between treatments in favor of losartan. A substudy of patients with $\mathrm{LVH}$ and isolated systolic hypertension in the LIFE trial demonstrated an even more impressive $40 \%$ stroke reduction. ${ }^{48} \mathrm{AF}$ is a known risk factor for stroke and losartan reduced the incidence of stroke by $51 \%$ (HR 0.49 [0.29-0.86]; $P=0.01)$ in patients with new-onset AF in the LIFE study. ${ }^{49}$ In the Study on Cognition and Prognosis in the Elderly (SCOPE), candesartan-based treatment reduced nonfatal stroke by $27.8 \%$ and all stroke by $23.6 \%$ compared with placebo in 4964 elderly patients. ${ }^{50}$ The Telmisartan Randomised AssessmeNt Study in ACE iNtolerant subjects with cardiovascular Disease (TRANSCEND) study reported a nonsignificant $17 \%$ reduction in stroke with telmisartan compared with placebo in high-risk patients who were intolerant to ACEIs. ${ }^{51}$ The TRANSCEND trial included a large proportion of patients without hypertension, in whom the benefits of BP lowering remains highly uncertain.

In addition to the strong data with $\mathrm{ARBs}$ for the primary prevention of stroke in placebo-controlled trials, several studies have indicated that ARBs are at least as effective as other antihypertensive agents for preventing stroke (Table 2). For example, in the CASE-J study there was no significant difference in cerebrovascular events between amlodipine- and candesartan-based regimens in Japanese high-risk patients $(\mathrm{n}=4728)$ with hypertension, including approximately $10 \%$ of patients with a history of cerebrovascular events. ${ }^{52}$ Recently, the Ongoing Telmisartan Alone and in Combination with Ramipril Global Endpoint Trial (ONTARGET) programme compared the effects of an ARB, telmisartan, with an ACEI, ramipril, and both agents in combination, in a range of patients at high risk of CV disease $(n=25620)$. ONTARGET reported no significant difference between ramipril and telmisartan for reducing stroke. ${ }^{53}$ In addition, a combination of ramipril and telmisartan provided no additional benefit to either monotherapy. These findings in ONTARGET may seem to contradict the hypothesis suggested by Boutitie et al ONTARGET enrolled individuals mostly at high risk of cardiac events rather than cerebrovascular events, where ramipril has already been shown to improve stroke in these patients. ${ }^{38}$ ACEIs are known to reduce cardiac risk and complications. ${ }^{39}$ 
Thus, it may be that many of the strokes in HOPE and ONTARGET occurred secondary to cardiac complications and this would explain some of the benefit of these agents on stroke. A recent meta-analysis covering 49924 patients in 6 trials (ONTARGET, Valsartan In Acute Myocardial Infarction Trial [VALIANT], Evaluation of Losartan In The Elderly study [ELITE] I and II, OPtimal Trial In Myocardial infarction with the Angiotensin II Antagonist Losartan [OPTIMAAL] and Diabetics Exposed to Telmisartan and enalaprIL [DETAIL]) comparing ACEIs and ARBs headto-head noted that, despite similar effects on MI, ARBs were associated with an $8 \%$ lower risk of stroke compared with ACEIs (OR 0.92 [95\% CI 0.85-0.99]; $P=0.036$ ). ${ }^{54}$

The benefits of ARBs for the prevention of secondary stroke are less well known and are undergoing intense scrutiny. Indeed, it has long been debated whether elevated BP should be lowered in the acute phase of stroke as it is feared that lowering BP would reduce cerebral blood perfusion. The Acute Candesartan Cilexetil Therapy in Stroke Survivors (ACCESS) study assessed the safety of a modest $\mathrm{BP}$ reduction by candesartan in the early treatment of stroke $(n=342)$ and showed significant reductions in 12-month mortality and vascular events with candesartan compared with placebo (OR 0.475 [95\% CI 0.252-0.895]). ${ }^{55}$ The Scandinavian Candesartan Acute Stroke Trial (SCAST) is designed to compare the effects of an ARB (candesartan) or placebo on $\mathrm{CV}$ morbidity and mortality in approximately 2500 patients with acute stroke $(<30$ hours) and elevated SBP $(\geq 140 \mathrm{mmHg}){ }^{56}$

The Morbidity and Mortality After Stroke, Eprosartan compared with nitrendipine for Secondary Prevention (MOSES) study was the first to compare an ARB with a short-acting CCB in a population of patients with hypertension and a history of cerebrovascular events. The trial reported a significant $(P=0.026) 25 \%$ reduction in cerebrovascular events with eprosartan compared with nitrendipine, despite similar reductions in BP. ${ }^{57}$ Thus, the MOSES and ACCESS studies demonstrate that ARBs are effective for the secondary prevention of stroke. In contrast, the PRoFESS (Prevention Regimen for Effectively Avoiding Second Strokes) study, the largest randomized double-blind secondary stroke prevention trial to date, ${ }^{58}$ did not find any significant benefit of telmisartan treatment compared with placebo on recurrent stroke in 20332 patients with an ischemic stroke within the last $<120$ days and who were stable (HR 0.95 [95\% CI 0.86-1.04]; $P=0.23$ ). ${ }^{59}$ The lack of a significant benefit between telmisartan and placebo in these patients could be due to methodological considerations, such as the inclusion of patients with low BP (baseline SBP was $144 \pm 17 \mathrm{mmHg}$ ) and carotid plaques. However, a prespecified subgroup analyses indicated no heterogeneity of effects on stroke across baseline SBP categories $(<135$, 135 to $\leq 150$ and $>150 \mathrm{mmHg}$ ). The presence of a J-curve relationship between BP and stroke, similar to that reported for a composite of all-cause mortality, nonfatal MI and nonfatal stroke and BP in patients with hypertension and coronary artery disease in the INternational VErapamil SRtrandolapril Study (INVEST), ${ }^{60}$ is unlikely to account for the lack of benefit with telmisartan in PRoFESS. Indeed, several studies have noted that a reduction in SBP to $<140 \mathrm{mmHg}$ is associated with a reduced risk of stroke in patients with a prior stroke/TIA ${ }^{61}$ or in high-risk hypertension. ${ }^{62}$ Moreover, an analysis of PROGRESS observed similar risk reduction in each of four subgroups defined by baseline BP of less than 120,120 to 139,140 to 159 , and $160 \mathrm{mmHg}$ or greater ( $P=0.5$ for homogeneity), indicating that achieving low BP levels should not be a concern in patients with prior cerebrovascular disease. ${ }^{63}$

In the Japanese Investigation of Kinetic Evaluation in Hypertensive Event and Remodelling Treatment (JIKEI HEART) study, valsartan has been examined in a Japanese population $(n=4728)$ with hypertension and other CV disease (patients with a cerebrovascular event in the previous 3 months were excluded) who were receiving usual treatment. Of patients who received valsartan on top of usual treatment, 29 had stroke (or TIA), compared with 48 in patients receiving non-ARB-based treatment (HR 0.60; $P=0.0280) .{ }^{64}$ The VALUE trial compared the effects of the ARB valsartan with the CCB amlodipine on cardiac morbidity and mortality in 15245 patients with hypertension and high CV risk. ${ }^{65}$ Almost $20 \%$ of the patients in VALUE had a history of stroke or TIA at baseline. No significant difference in the incidence of stroke was noted between the two treatment arms. ${ }^{62,65}$ In the VALUE study, an ARB was shown to reduce AF significantly more than amlodipine, ${ }^{66}$ although this was not associated with a significant reduction in stroke, ${ }^{65}$ possibly due to the small numbers of patients with these events. Thus, valsartan and other ARBs appear to reduce the risk of stroke more than placebo and to a similar extent as CCBs in primary prevention populations.

In general, the cerebrovascular benefits of ARBs seem to be class-related rather than drug-related. ${ }^{54}$ All ARBs might be expected to reduce the risk of stroke. Any differences in stroke protection between individual trials may be accounted for by difference in study design and/or patient populations. 


\section{What is the source of the benefit of ARBs and CCBs on stroke?}

Reductions in BP are the most important determinant of CV outcome, and stroke in particular. ${ }^{29}$ Most of the benefit of amlodipine on stroke can be explained by differences in BP control. ${ }^{35}$ The relationship between BP and stroke is strong and even small changes in BP between treatments can result in differences in stroke (Figure 1). 16,67,68 However, there does appear to be a BP-independent component that contributes to the benefit of CCBs on stroke. ${ }^{31,35}$ Similarly, reductions in the incidence of stroke with ARBs in the MOSES and ACCESS studies occurred despite reductions in BP being similar to that observed with the comparators used, suggesting that these agents also have some BP-independent benefits. Preclinical studies also support a BP-independent effect of ARBs on stroke. In normotensive rats, pretreatment of an ARB at a subantihypertensive dose was more effective than an ACEI for reducing infarct size and neurological deficits following transient focal ischemia. ${ }^{69}$

There are several theoretical mechanisms whereby ARBs and $\mathrm{CCBs}$ might prevent stroke beyond $\mathrm{BP}$ reductions. For example, increased carotid intima-media thickness (CIMT) is associated with an increased risk for stroke ${ }^{70}$ and it is known that CCBs can reduce carotid intima-media thickening to a

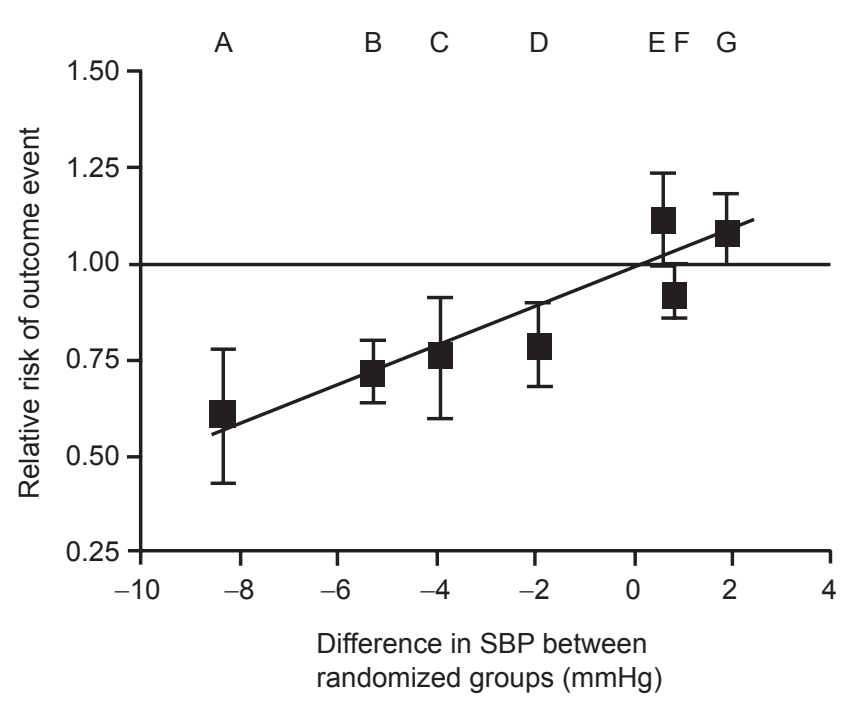

Figure I Relationship between SBP and stroke. Reprinted from The Lancet, 362, Turnbull F; Blood Pressure Lowering Treatment Trialists' Collaboration. Effects of different blood-pressure-lowering regimens on major cardiovascular events: results of prospectively-designed overviews of randomised trials, I527-1535. ${ }^{67}$ Copyright (C) 2003, with permission from Elsevier.

Notes: $A, C C B$ vs placebo; $B, A C E l$ vs placebo; $C$, more intensive vs less intensive BP-lowering; D, ARB vs control; E, ACEl vs $C C B ; F, C C B$ vs diuretic or $\beta$-blocker; $G, A C E I$ vs diuretic and $\beta$-blocker.

Abbreviations: $A C E I$, angiotensin-converting enzyme inhibitor; $A R B$, angiotensin receptor blocker; BP, blood pressure; CCB, calcium channel blocker; SBP, systolic blood pressure. greater degree than observed with ACEIs, despite similar reductions in BP. ${ }^{71}$ It has been suggested that this effect on CIMT might explain the superior protection against stroke with these agents. ${ }^{71}$ ARBs have also been shown to reduce CIMT in patients with hypertension, ${ }^{72-74}$ an effect greater than observed with atenolol despite similar reductions in BP. ${ }^{72}$ This effect on CIMT observed with ARBs is thought to be mediated by improvements in nitric oxide production and decreases in oxidative stress. ${ }^{74}$

Increased left ventricular mass (LVM) is a risk factor for stroke. ${ }^{6}$ Increased LVM is also a risk factor for $\mathrm{AF},{ }^{75} \mathrm{a}$ known cause of stroke. ${ }^{76,77}$ Thus, a beneficial effect of ARBs and $\mathrm{CCBs}$ on $\mathrm{LVH}$ relative to other antihypertensive agents could also explain the strong supportive data for stroke prevention with these agents. Indeed, in a meta-analysis of the effects of antihypertensive treatment on LVM, CCBs and ARBs were reported to reduce LVM index by $11 \%$ and $13 \%$, respectively, which are numerically greater reductions than those observed with other antihypertensive agents. ${ }^{78}$

Changes in central aortic pressure but not peripheral BP could explain some differences between CCBs and other agents. Despite similar brachial pressures, amlodipine-based treatment reduced central SBP more than atenolol-based treatment in the ASCOT Conduit Artery Function Evaluation (CAFÉ) substudy. ${ }^{79}$ It has been suggested that heart rate is a major determinant of the difference between central and brachial BP and might account for the less effective lowering of central BP with atenolol. ${ }^{80}$ Thus, the effect on central BP and heart rate could account for some of the difference in stroke between atenolol and amlodipine in ASCOT. When assessing possible relationships of BP and stroke, many studies are limited by the use of sitting BP determined in the clinic. However, there are other BP parameters, such as central BP, night-time and 24-hour BP, BP variability and heart rate, which might also contribute to treatment differences in stroke, and further studies are required.

Finally, experiments in animals suggest that ARBs and CCBs might have BP-independent effects that might influence stroke outcomes. For example, studies in spontaneously hypertensive rats suggest that ARB treatment can reduce inflammation in cerebral microvessels ${ }^{81}$ and normalize the cerebral blood flow following ischemia. ${ }^{82}$ Moreover, in a rat model of cerebral ischemia, ARB treatment reduced middle cerebral artery (MCA) media thickness and infarct area following occlusion of MCA. ${ }^{83}$ Studies in rats also showed that the protection in cerebral circulation by improving cerebral blood flow autoregulation and reducing superoxide production, occurred with doses that do not reduce BP. ${ }^{84}$ 
A similar effect has also been observed with amlodipine in ApoE knockout mice model of stroke. ${ }^{85}$ Although these effects have been observed in animal models, these data should be cautiously translated to humans where these mechanisms have not been readily observed.

Although it is possible to speculate about the various possible cerebroprotective mechanisms of CCBs and ARBs, reductions in BP are key in preventing stroke. Moreover, caution should be used when comparing and interpreting differences in stroke reductions between clinical trials, as differences in trial design and selection criteria may influence the data. A meta-analysis of head-to head ACEI and ARB trials noting a slight benefit in stroke prevention with ARBs could not attribute any mechanistic basis to the cerebrovascular protection with ARBs, and it cannot be excluded that differences in blood pressure accounted for this observation. ${ }^{54}$

\section{Potential of combination therapy}

As indicated previously, the relationship between BP reductions and the risk of stroke is well established (Figure 1). ${ }^{67}$ It has been suggested, therefore, that rapid, sustained reductions in $\mathrm{BP}$ are necessary for the optimal prevention of stroke in patients with hypertension. ${ }^{45}$ Indeed, in VALUE the $\mathrm{BP}$ response after 1 month predicted $\mathrm{CV}$ events and survival. ${ }^{62}$ Combination therapy has been suggested as an approach to achieve large, rapid reductions in BP and help optimize the reduction in stroke risk. ${ }^{45}$

Few studies have assessed the benefits of combination therapy compared with monotherapy. The Felodipine Event Reduction (FEVER) study has compared a combination therapy (hydrochlorothiazide [HCTZ]/felodipine extended release) with monotherapy (HCTZ/placebo) in 9800 Chinese patients with hypertension and other $\mathrm{CV}$ risk factors. It was noted that addition of felodipine extended release to HCTZ treatment reduced BP by an additional 4.2/2.1 $\mathrm{mmHg}$ and reduced the incidence of fatal/nonfatal stroke by $27 \%$ vs HCTZ/placebo. ${ }^{86}$ Thus, these studies would support the use of greater BP reductions with combination therapy to provide greater reductions in the risk of stroke. In contrast, combining an ARB and an ACEI in ONTARGET provided no additional benefit over monotherapy for reducing stroke despite an incremental reduction in $\mathrm{BP}$ of 2.4/1.4 mmHg over ramipril monotherapy. ${ }^{53}$ Therefore, the choice of agents for combination may be an important consideration.

The Avoiding Cardiovascular events through COMbination therapy in Patients Living with Systolic Hypertension (ACCOMPLISH) trial compared the clinical benefits of two single-pill combinations of antihypertensive agents (benazepril/HCTZ and amlodipine/benazepril) on $\mathrm{CV}$ mortality and morbidity in high-risk patients with hypertension. ${ }^{87}$ It was noted that the $\mathrm{CCB} / \mathrm{ACEI}$ combination decreased $\mathrm{CV}$ morbidity and mortality significantly more than the ACEI/diuretic (20\% relative risk reduction; $P<0.001)$ despite similar reductions in BP. ${ }^{88}$ There were numerically fewer strokes (fatal and nonfatal) with the $\mathrm{CCB} / \mathrm{ACEI}$ compared with the $\mathrm{CCB} /$ diuretic (16\% risk reduction) in ACCOMPLISH although this did not achieve statistical significance $(P=0.16)$, and it may be that there were insufficient events to establish a difference between treatments in this outcome.

In the JIKEI HEART study, addition of valsartan to conventional therapy was more effective at reducing stroke compared with non-ARB-based therapy. ${ }^{64}$ Given that the majority of patients were receiving antihypertensive agents at baseline, this may suggest that that ARB-based combinations might have some utility in preventing stroke compared with non-ARB-based combinations.

In PROGRESS, combination therapy with perindopril and indapamide reduced BP by $12 / 5 \mathrm{mmHg}$ and lowered the risk of recurrent stroke by $43 \%$ compared with placebo. However, single drug therapy with perindopril reduced BP by only $5 / 3 \mathrm{mmHg}$ and resulted in no significant reduction in recurrent stroke risk. ${ }^{40,89} \mathrm{On}$ the basis of these data, the US JNC VII guidelines recommend either treatment with a diuretic, an ACE inhibitor or both agents in combination for the prevention of recurrent stroke. ${ }^{90}$ However, these recommendations were made before the results of studies investigating the use of $\mathrm{ARBs}$ for the prevention of secondary stroke (MOSES, ACCESS and PROFeSS) were published. The ESH-ESC guidelines recognize that antihypertensive treatment markedly reduces the incidence of stroke recurrence in patients with a history of stroke or TIA, and a BP goal of $130 / 80 \mathrm{mmHg}$ is recommended. ${ }^{91}$ Since evidence from trials suggests that the benefit predominantly depends on BP lowering, the ESH-ESC guidelines indicate that all available drugs and 'rational' combinations can be used. ${ }^{91}$ The benefits of BP lowering in the setting of acute stroke requires more research and current recommendations are that antihypertensive treatment should start when poststroke clinical conditions are stable, usually several days after the event. ${ }^{91}$ Both JNC VII and ESH-ESC guidelines recognize that combination therapy is required to reduce BP to recommended levels in a large proportion of patients. ${ }^{90,91}$ In addition, more evidence is needed before the specific cerebrovascular 
protective properties of individual agents or particular combinations are established.

\section{Rationale for a CCB/ARB single-pill combination for stroke prevention}

Multiple regulatory pathways are involved in the regulation of $\mathrm{BP}$, and therefore combinations of agents that act by different mechanisms can have complementary actions and be more effective at reducing BP than monotherapy. ${ }^{92}$ To optimize the benefits on stroke prevention it seems logical, when combining agents, to employ agents that (1) have complementary effects, (2) are effective at reducing BP, (3) might possess BP-independent effects, such as those discussed earlier, and (4) are associated with strong supportive evidence for the prevention of stoke. As indicated earlier, protection against stroke was greater with ARBs than with ACEIs. ${ }^{54}$

Individually, amlodipine and ARBs seem to possess strong clinical trial data for antihypertensive agents in the protection against stroke. ${ }^{93}$ Clinical studies have demonstrated that a combination of valsartan and amlodipine is an effective antihypertensive strategy capable of reducing BP more effectively than either treatment as monotherapy. ${ }^{94-96}$ Indeed, amlodipine/valsartan 5 to $10 / 160 \mathrm{mg}$ reduces BP across all stages of hypertension, with reductions from baseline in mean sitting systolic BP of 20, 30 and 36 to $43 \mathrm{mmHg}$, respectively, in patients with mild, moderate and severe hypertension. ${ }^{94,96,97}$ The large BP reductions with this combination coupled with the data supporting the protective effect of these agents as monotherapy would suggest that this combination might be an effective approach for stroke prevention. Indeed, in the JIKEI HEART study, a large proportion $(67 \%)$ of patients in this study were also receiving a CCB and valsartan therapy reduced the risk of stroke by $40 \%$ compared with non-ARB-based therapy ${ }^{64}$ These data may suggest that combining valsartan with a $\mathrm{CCB}$, such as amlodipine, has potential for protecting against stroke. However, studies on this combination in the context of stroke prevention have not been conducted to date.

Finally, the presence of $\mathrm{CCB} / \mathrm{ARB}$ combinations in single-pill formulation may have indirect benefits. It is known that the use of single-pill antihypertensive combinations can improve persistence with therapy beyond that provided by free combinations..$^{98}$ Patients who persist on antihypertensive therapy have been reported to have a $28 \%$ reduction in the relative risk of stroke compared with patients who do not persist with therapy. ${ }^{20}$ Thus, the use of single-pill antihypertensive combinations may help to reduce stroke through improvements in adherence.

\section{Concluding remarks}

In conclusion, antihypertensive agents can reduce the risk of stroke, predominantly by reductions in BP. However, there may be some differences in stroke protection between antihypertensive treatments, which may not be explained solely by differences in BP. Possible mechanisms for this additional benefit might include reductions in CIMT, LVH or central BP, or improvements in cerebral blood flow autoregulation. ARBs and CCBs have particularly strong supportive data for a protective effect against stroke. The choice of these agents or combinations of these agents could help to optimize the cerebrovascular benefits of antihypertensive treatment. However, further studies are needed to confirm the benefits of different combination strategies on stroke.

\section{Acknowledgments and disclosures}

Writing assistance in drafting this article was provided by Graham Allcock, a professional medical writer for ACUMED $^{\circledR}$. Financial support for this assistance was provided by Novartis Pharma AG.

Professor Wang has received consulting and lecture fees from Astra-Zeneca, GSK, Novartis, Pfizer, Sanofi-Aventis, Servier, and Takeda, and grants from Omron and Pfizer via the Shanghai Institute of Hypertension.

\section{References}

1. Meairs S, Wahlgren N, Dirnagl U, Lindvall O, Rothwell P, Baron JC, et al. Stroke research priorities for the next decade - a representative view of the European scientific community. Cerebrovasc Dis. 2006; 22(2-3):75-82.

2. WHO atlas of heart disease and stroke. http://www.who.int/ cardiovascular_diseases/en/cvd_atlas_15_burden_stroke.pdf. Accessed July 8, 2009.

3. Truelsen T, Piechowski-Jóźwiak B, Bonita R, Mathers C, Bogousslavsky J, Boysen G. Stroke incidence and prevalence in Europe: a review of available data. Eur J Neurol. 2006;13(6):581-598.

4. Paul SL, Srikanth VK, Thrift AG. The large and growing burden of stroke. Curr Drug Targets. 2007;8(7):786-793.

5. Goldstein LB, Adams R, Alberts MJ, Appel LJ, Brass LM, Bushnell CD, et al. American Heart Association; American Stroke Association Stroke Council. Primary prevention of ischemic stroke: a guideline from the American Heart Association/American Stroke Association Stroke Council: cosponsored by the Atherosclerotic Peripheral Vascular Disease Interdisciplinary Working Group; Cardiovascular Nursing Council; Clinical Cardiology Council; Nutrition, Physical Activity, and Metabolism Council; and the Quality of Care and Outcomes Research Interdisciplinary Working Group. Circulation. 2006;113(24):e873-e923.

6. Di Tullio MR, Zwas DR, Sacco RL, Sciacca RR, Homma S. Left ventricular mass and geometry and the risk of ischemic stroke. Stroke. 2003;34(10):2380-2384.

7. Lüders S. Drug therapy for the secondary prevention of stroke in hypertensive patients: current issues and options. Drugs. 2007;67(7): 955-963.

8. Coull AJ, Lovett JK, Rothwell PM; Oxford Vascular Study. Population based study of early risk of stroke after transient ischaemic attack or minor stroke: implications for public education and organisation of services. BMJ. 2004;328(7435):326. 
9. Xu G, Liu X, Wu W, Zhang R, Yin Q. Recurrence after ischemic stroke in Chinese patients: impact of uncontrolled modifiable risk factors. Cerebrovasc Dis. 2007;23(2-3):117-120.

10. Singh RB, Suh IL, Singh VP, Chaithiraphan S, Laothavorn P, Sy RG, et al. Hypertension and stroke in Asia: prevalence, control and strategies in developing countries for prevention. J Hum Hypertens. 2000;14(10-11):749-763.

11. Lewington S, Clarke R, Qizilbash N, Peto R, Collins R; Prospective Studies Collaboration. Age-specific relevance of usual blood pressure to vascular mortality: a meta-analysis of individual data for one million adults in 61 prospective studies. Lancet. 2002;360(9349); 1903-1913.

12. Lawes CM, Vander Hoorn S, Rodgers A; International Society of Hypertension. Global burden of blood-pressure-related disease, 2001. Lancet. 2008;371(9623):1513-1518.

13. Gorelick PB. New horizons for stroke prevention: PROGRESS and HOPE. Lancet Neurol. 2002;1(3):149-156.

14. Mancia G, Grassi G. Secondary prevention of stroke: old and new evidence. Aging Clin Exp Res. 2002;14(3):216-220.

15. Grassi G, Arenare F, Trevano FQ, Dell'Oro R, Mancia AG. Primary and secondary prevention of stroke by antihypertensive treatment in clinical trials. Curr Hypertens Rep. 2007;9(4):299-304.

16. Staessen JA, Wang JG, Thijs L. Cardiovascular protection and blood pressure reduction: a meta-analysis. Lancet. 2001;358(9290): 1305-1315.

17. Lawes CM, Rodgers A, Bennett DA, Parag V, Suh I, Ueshima H, et al. Asia Pacific Cohort Studies Collaboration. Blood pressure and cardiovascular disease in the Asia Pacific region. J Hypertens. 2003;21(4):707-716.

18. Lawes CM, Bennett DA, Feigin VL, Rodgers A. Blood pressure and stroke: an overview of published reviews. Stroke. 2004;35(4): 1024-1033.

19. Gueyffier F, Boissel JP, Boutitie F, Pocock S, Coope J, Cutler, et al. Effect of antihypertensive treatment in patients having already suffered from stroke. Gathering the evidence. The INDANA (INdividual Data Analysis of ANtihypertensive intervention trials) project collaborators. Stroke. 1997;28(12):2557-2562.

20. Breekveldt-Postma NS, Penning-van Beest FJ, Siiskonen SJ, Falvey H, Vincze G, Klungel $\mathrm{OH}$, et al. The effect of discontinuation of antihypertensives on the risk of acute myocardial infarction and stroke. Curr Med Res Opin. 2008;24(1):121-127.

21. Pitt B, Byington RP, Furberg CD, Hunninghake DB, Mancini GB, Miller ME, et al. Effect of amlodipine on the progression of atherosclerosis and the occurrence of clinical events. PREVENT Investigators Circulation. 2000;102(13):1503-1510.

22. Staessen JA, Fagard R, Thijs L, Celis H, Arabidze GG, Birkenhäger WH, et al. Randomised double-blind comparison of placebo and active treatment for older patients with isolated systolic hypertension. The Systolic Hypertension in Europe (Syst-Eur) Trial Investigators. Lancet. 1997;350(9080):757-764.

23. Staessen JA, Thijs L, Fagard RH, Birkenhäger WH, Arabidze GG, Babeanu S, et al. Calcium channel blockade and cardiovascular prognosis in the European trial on isolated systolic hypertension. Hypertension. 1998;32(3):410-416.

24. Wang JG, Staessen JA, Gong L, Liu L. Chinese trial on isolated systolic hypertension in the elderly. Systolic Hypertension in China (Syst-China) Collaborative Group. Arch Intern Med. 2000;160(2):211-220.

25. Lubsen J, Wagener G, Kirwan BA, de Brouwer S, Poole-Wilson PA; ACTION (A Coronary disease Trial Investigating Outcome with Nifedipine GITS) investigators. Effect of long-acting nifedipine on mortality and cardiovascular morbidity in patients with symptomatic stable angina and hypertension: the ACTION trial. J Hypertens. 2005;23(3):641-648.

26. Dowlatshahi D, Fang J, Kawaja M, Hakim A. Use of calcium channel blockers after stroke is not associated with poor outcome: a cohort from the registry of the Canadian stroke network. J Neurol. 2006;253(11):1478-1483.
27. Bangalore S, Messerli FH. A review of stroke in patients with hypertension and coronary artery disease: Focus on calcium channel blockers. Int J Clin Pract. 2006;60(10):1281-1286.

28. Staessen JA, Li Y, Thijs L, Wang JG. Blood pressure reduction and cardiovascular prevention: an update including the 2003-2004 secondary prevention trials. Hypertens Res. 2005;28(5):385-407.

29. Verdecchia P, Reboldi G, Angeli F, Gattobigio R, Bentivoglio M, Thijs L, et al. Angiotensin-converting enzyme inhibitors and calcium channel blockers for coronary heart disease and stroke prevention. Hypertension. 2005;46(2):386-392.

30. Dahlöf B, Sever PS, Poulter NR, Wedel H, Beevers DG, Caulfield M, et al. ASCOT Investigators. Prevention of cardiovascular events with an antihypertensive regimen of amlodipine adding perindopril as required vs atenolol adding bendroflumethiazide as required, in the Anglo-Scandinavian Cardiac Outcomes Trial-Blood Pressure Lowering Arm (ASCOT-BPLA): a multicentre randomised controlled trial. Lancet. 2005;366(9489):895-906.

31. Poulter NR, Wedel H, Dahlöf B, Sever PS, Beevers DG, Caulfield M, et al. ASCOT Investigators. Role of blood pressure and other variables in the differential cardiovascular event rates noted in the AngloScandinavian Cardiac Outcomes Trial-Blood Pressure Lowering Arm (ASCOT-BPLA). Lancet. 2005;366(9489):907-913.

32. Nissen SE, Tuzcu EM, Libby P, Thompson PD, Ghali M, Garza D, et al. CAMELOT Investigators. Effect of antihypertensive agents on cardiovascular events in patients with coronary disease and normal blood pressure: the CAMELOT study: a randomized controlled trial. JAMA. 2004;292(18):2217-2225.

33. ALLHAT Collaborative Research Group. Major outcomes in high-risk hypertensive patients randomized to angiotensin-converting enzyme inhibitor or calcium channel blocker vs diuretic: The Antihypertensive and Lipid-Lowering Treatment to Prevent Heart Attack Trial (ALLHAT). JAMA. 2002;288(23):2981-2997.

34. Leenen FH, Nwachuku CE, Black HR, Cushman WC, Davis BR, Simpson LM, et al. ALLHAT Collaborative Research Group. Clinical events in high-risk hypertensive patients randomily assigned to calcium channel blocker vs angiotensin-converting enzyme inhibitor in the antihypertensive and lipid-lowering treatment to prevent heart attack trial. Hypertension. 2006;48(3):374-384.

35. Wang JG, Li Y, Franklin SS, Safar M. Prevention of stroke and myocardial infarction by amlodipine and angiotensin receptor blockers. A quantitative overview. Hypertension. 2007;50(1):181-188.

36. Iadecola C, Gorelick PB. Hypertension, angiotensin, and stroke: beyond blood pressure. Stroke. 2004;35(2):348-350.

37. Schrader J, Kulschewski A, Dendorfer A. Inhibition of the renin-angiotensin system and the prevention of stroke. Am J Cardiovasc Drugs. 2007;7(1):25-37.

38. Bosch J, Yusuf S, Pogue J, Sleight P, Lonn E, Rangoonwala B, et al. HOPE Investigators. Heart outcomes prevention evaluation. Use of ramipril in preventing stroke: double blind randomised trial. BMJ. 2002;324(7339):699-702.

39. Yusuf S, Sleight P, Pogue J, Bosch J, Davies R, Dagenais G. Effects of an angiotensin-converting-enzyme inhibitor, ramipril, on cardiovascular events in high-risk patients. The Heart Outcomes Prevention Evaluation Study Investigators. N Engl J Med. 2000;342(3):145-153.

40. PROGRESS Collaborative Group. Randomised trial of a perindopril-based blood pressure-lowering regimen among 6105 individuals with previous stroke or transient ischaemic attack. Lancet. 2001;358(9287):1033-1041.

41. Flather MD, Yusuf S, Køber L, Pfeffer M, Hall A, Murray G, et al. Long-term ACE-inhibitor therapy in patients with heart failure or left-ventricular dysfunction: a systematic overview of data from individual patients. ACE-Inhibitor Myocardial Infarction Collaborative Group. Lancet. 2000;355(9215):1575-1581.

42. Hansson L, Lindholm LH, Niskanen L, Lanke J, Hedner T, Niklason A, et al. Effect of angiotensin-converting-enzyme inhibition compared with conventional therapy on cardiovascular morbidity and mortality in hypertension: the Captopril Prevention Project (CAPPP) randomised trial. Lancet. 1999;353(9153):611-616. 
43. Niskanen L, Hedner T, Hansson L, Lanke J, Niklason A; CAPPP Study Group. Reduced cardiovascular morbidity and mortality in hypertensive diabetic patients on first-line therapy with an ACE inhibitor compared with a diuretic/beta blocker-based treatment regimen: a subanalysis of the Captopril Prevention Project. Diabetes Care. 2001;24(12):2091-2096.

44. Boutitie F, Oprisiu R, Achard JM, Mazouz H, Wang J, Messerli FH, et al. Does a change in angiotensin II formation caused by antihypertensive drugs affect the risk of stroke? A meta-analysis of trials according to treatment with potentially different effects on angiotensin II. J Hypertens. 2007;25(8):1543-1553.

45. Epstein BJ, Gums JG. Can the renin-angiotensin system protect against stroke? A focus on angiotensin II receptor blockers. Pharmacotherapy. 2005;25(4):531-539.

46. Fournier A, Messerli FH, Achard JM, Fernandez L. Cerebroprotection mediated by angiotensin II: a hypothesis supported by recent randomized clinical trials. J Am Coll Cardiol. 2004;43(8):1343-1347.

47. Dahlöf B, Devereux RB, Kjeldsen SE, Julius S, Beevers G, de Faire U, et al. LIFE Study Group. Cardiovascular morbidity and mortality in the Losartan Intervention For Endpoint reduction in hypertension study (LIFE): a randomised trial against atenolol. Lancet. 2002;359(9311):995-1003.

48. Kjeldsen SE, Dahlöf B, Devereux RB, Julius S, Aurup P, Edelman J, et al. LIFE (Losartan Intervention for Endpoint Reduction) Study Group. Effects of losartan on cardiovascular morbidity and mortality in patients with isolated systolic hypertension and left ventricular hypertrophy: a Losartan Intervention for Endpoint Reduction (LIFE) substudy. JAMA. 2002;288(12):1491-1498.

49. Wachtell K, Lehto M, Gerdts E, Olsen MH, Hornestam B, Dahlöf B, et al. Angiotensin II receptor blockade reduces new-onset atrial fibrillation and subsequent stroke compared to atenolol: the Losartan Intervention For End Point Reduction in Hypertension (LIFE) study. $J$ Am Coll Cardiol. 2005;45(5):712-719.

50. Lithell H, Hansson L, Skoog I, Elmfeldt D, Hofman A, Olofsson B, et al. SCOPE Study Group. The Study on Cognition and Prognosis in the Elderly (SCOPE): principal results of a randomized double-blind intervention trial. J Hypertens. 2003;21(5):875-886.

51. The Telmisartan Randomised AssessmeNt Study in ACE iNtolerant subjects with cardiovascular Disease (TRANSCEND) Investigators. Effects of the angiotensin-receptor blocker telmisartan on cardiovascular events in high-risk patients intolerant to angiotensinconverting enzyme inhibitors: a randomised controlled trial. Lancet. 2008;372(9644):1174-1183.

52. Ogihara T, Nakao K, Fukui T, Fukiyama K, Ueshima K, Oba K, et al. Candesartan Antihypertensive Survival Evaluation in Japan Trial Group. Effects of candesartan compared with amlodipine in hypertensive patients with high cardiovascular risks: candesartan antihypertensive survival evaluation in Japan trial. Hypertension. 2008;51(2):393-398.

53. ONTARGET Investigators, Yusuf S, Teo KK, Pogue J, Dyal L, Copland I, et al. Telmisartan, ramipril, or both in patients at high risk for vascular events. N Engl J Med. 2008;358(15):1547-1559.

54. Reboldi G, Angeli F, Cavallini C, Gentile G, Mancia G, Verdecchia P. Comparison between angiotensin-converting enzyme inhibitors and angiotensin receptor blockers on the risk of myocardial infarction, stroke and death: a meta-analysis. J Hypertens. 2008;26(7):1282-1289.

55. Schrader J, Lüders S, Kulschewski A, Berger J, Zidek W, Treib J, et al. Acute Candesartan Cilexetil Therapy in Stroke Survivors Study Group. The ACCESS Study: evaluation of Acute Candesartan Cilexetil Therapy in Stroke Survivors. Stroke. 2003;34(7):1699-1703.

56. ClinicalTrials.gov [webpage]. Scandinavian Candesartan Acute Stroke Tirial (SCAST). [updated 2009 May 13; cited 2008 July 15]. Available from: http://clinicaltrials.gov/ct2/show/NCT00120003.

57. Schrader J, Lüders S, Kulschewski A, Hammersen F, Plate K, Berger J, et al. MOSES Study Group. Morbidity and mortality after stroke, eprosartan compared with nitrendipine for secondary prevention. Principal results of a prospective randomized controlled study (MOSES). Stroke. 2005;36(6):1218-1226.
58. Diener HC, Sacco R, Yusuf S; PRoFESS Study Group. Rationale, design and baseline data of a randomized, double-blind, controlled trial comparing two antithrombotic regimens (a fixed-dose combination of extended-release dipyridamole plus ASA with clopidogrel) and telmisartan vs placebo in patients with strokes: the Prevention Regimen for Effectively Avoiding Second Strokes Trial (PRoFESS). Cerebrovasc Dis. 2007;23(5-6):368-380.

59. Yusuf S, Diener HC, Sacco RL, Cotton D, Ounpuu S, Lawton WA, et al. PRoFESS Study Group. Telmisartan to prevent recurrent stroke and cardiovascular events. $N$ Engl J Med. 2008;359(12):1225-1237.

60. Messerli FH, Mancia G, Conti CR, Hewkin AC, Kupfer S, Champion A, et al. Dogma disputed: can aggressively lowering blood pressure in hypertensive patients with coronary artery disease be dangerous? Ann Intern Med. 2006;144(12):884-893.

61. Coca A, Messerli FH, Benetos A, Zhou Q, Champion A, Cooper-DeHoff RM, et al. Predicting stroke risk in hypertensive patients with coronary artery disease: a report from the INVEST. Stroke. 2008;39(2):343-348

62. Weber MA, Julius S, Kjeldsen SE, Brunner HR, Ekman S, Hansson L, et al. Blood pressure dependent and independent effects of antihypertensive treatment on clinical events in the VALUE trial. Lancet. 2004;363(9426):2049-2051.

63. Arima H, Chalmers J, Woodward M, Anderson C, Rodgers A, Davis S, et al. PROGRESS Collaborative Group. Lower target blood pressures are safe and effective for the prevention of recurrent stroke: the PROGRESS trial. J Hypertens. 2006;24(6):1201-1208.

64. Mochizuki S, Dahlöf B, Shimizu M, Ikewaki K, Yoshikawa M, Taniguchi I, et al. Jikei Heart Study group. Valsartan in a Japanese population with hypertension and other cardiovascular disease (Jikei Heart Study): a randomised, open-label, blinded endpoint morbidity-mortality study. Lancet. 2007;369(9571):1431-1439.

65. Julius S, Kjeldsen SE, Weber M, Brunner HR, Ekman S, Hansson L, et al. VALUE trial group. Outcomes in hypertensive patients at high cardiovascular risk treated with regimens based on valsartan or amlodipine: the VALUE randomised trial. Lancet. 2004;363(9426):2022-2031.

66. Schmieder RE, Kjeldsen SE, Julius S, McInnes GT, Zanchetti A, Hua TA; VALUE Trial Group. Reduced incidence of new-onset atrial fibrillation with angiotensin II receptor blockade: the VALUE trial. J Hypertens. 2008;26(3):403-411.

67. Turnbull F; Blood Pressure Lowering Treatment Trialists' Collaboration. Effects of different blood-pressure-lowering regimens on major cardiovascular events: results of prospectively-designed overviews of randomised trials. Lancet. 2003;362(9395):1527-1535.

68. Messerli FH, Staessen JA. Amlodipine better than lisinopril? How one randomized clinical trial ended fallacies from observational studies. Hypertension. 2006;48(3):359-361.

69. Thone-Reineke C, Krikov M, Schmerbach K, Muller S, Villringer A, Steckelings U, et al. Comparison of the effect of systematic pretreatment with telmisartan, ramipril and their combination on neurological status and infarct volume in rats after stroke. J Hypertens. 2008; 26(Suppl.1):S1.

70. Lorenz MW, Markus HS, Bots ML, Rosvall M, Sitzer M. Prediction of clinical cardiovascular events with carotid intima-media thickness: a systematic review and meta-analysis. Circulation. 2007;115(4):459-467.

71. Wang JG, Staessen JA, Li Y, Van Bortel LM, Nawrot T, Fagard R, et al. Carotid intima-media thickness and antihypertensive treatment: a meta-analysis of randomized controlled trials. Stroke. 2006;37(7): 1933-1940.

72. Mörtsell D, Malmqvist K, Held C, Kahan T. Irbesartan reduces common carotid artery intima-media thickness in hypertensive patients when compared with atenolol: the Swedish Irbesartan Left Ventricular Hypertrophy Investigation vs Atenolol (SILVHIA) study. J Intern Med. 2007;261(5):472-479.

73. Olsen MH, Wachtell K, Neland K, Bella JN, Rokkedal J, Dige-Petersen H, et al. Losartan but not atenolol reduce carotid artery hypertrophy in essential hypertension. A LIFE substudy. Blood Press. 2005;14(3):177-183. 
74. Ono H, Minatoguchi S, Watanabe K, Yamada Y, Mizukusa T, Kawasaki H, et al. Candesartan decreases carotid intima-media thickness by enhancing nitric oxide and decreasing oxidative stress in patients with hypertension. Hypertens Res. 2008;31(2):271-279.

75. Verdecchia P, Reboldi G, Gattobigio R, Bentivoglio M, Borgioni C, Angeli $\mathrm{F}$, et al. Atrial fibrillation in hypertension: predictors and outcome. Hypertension. 2003;41(2):218-223.

76. Sampson UK, Pfeffer MA, McMurray JJ, Lokhnygina Y, White HD, Solomon SD, et al. VALIANT Trial Investigators. Predictors of stroke in high-risk patients after acute myocardial infarction: insights from the VALIANT Trial. Eur Heart J. 2007;28(6):685-691.

77. Wattigney WA, Mensah GA, Croft JB. Increasing trends in hospitalization for atrial fibrillation in the United States, 1985 through 1999: implications for primary prevention. Circulation. 2003;108(6):711-716.

78. Klingbeil AU, Schneider M, Martus P, Messerli FH, Schmieder RE. A meta-analysis of the effects of treatment on left ventricular mass in essential hypertension. Am J Med. 2003;115(1):41-46.

79. Williams B, Lacy PS, Thom SM, Cruickshank K, Stanton A, Collier D, et al. CAFE Investigators; Anglo-Scandinavian Cardiac Outcomes Trial Investigators; CAFE Steering Committee and Writing Committee. Differential impact of blood pressure-lowering drugs on central aortic pressure and clinical outcomes: principal results of the Conduit Artery Function Evaluation (CAFE) study. Circulation. 2006;113(9):1213-1225.

80. Lacy PS, Williams B. Impact of heart rate on the differential impact of blood pressure lowering drugs on central and peripheral pressures: Data from the Conduit Artery Function Evaluation (CAFÉ) study. J Hypertens. 2008;26(Suppl.1):S459.

81. Ando H, Zhou J, Macova M, Imboden H, Saavedra JM. Angiotensin II AT1 receptor blockade reverses pathological hypertrophy and inflammation in brain microvessels of spontaneously hypertensive rats. Stroke. 2004;35(7):1726-1731.

82. Nishimura Y, Ito T, Saavedra JM. Angiotensin II AT(1) blockade normalizes cerebrovascular autoregulation and reduces cerebral ischemia in spontaneously hypertensive rats. Stroke. 2000;31(10):2478-2486.

83. Ito T, Yamakawa H, Bregonzio C, Terrón JA, Falcón-Neri A, Saavedra JM. Protection against ischemia and improvement of cerebral blood flow in genetically hypertensive rats by chronic pretreatment with an angiotensin II AT1 antagonist. Stroke. 2002;33(9):2297-2303.

84. Kumai Y, Ooboshi H, Ago T, Ishikawa E, Takada J, Kamouchi M, et al. Protective effects of angiotensin II type 1 receptor blocker on cerebral circulation independent of blood pressure. Exp Neurol. 2008;210(2):441-448.

85. Mogi M, Iwai M, Chen R, Iwanami J, Ide A, Tsukuda K, et al. Amlodipine treatment reduces stroke size in apolipoprotein E-deficient mice. Am J Hypertens. 2006;19(11):1144-1149.

86. Liu L, Zhang Y, Liu G, Li W, Zhang X, Zanchetti A; FEVER Study Group. The felodipine event reduction (FEVER) study: a randomized long-term placebo-controlled trial in Chinese hypertensive patients. J Hypertens. 2005;23(12):2157-2172.

87. Jamerson KA, Bakris GL, Wun CC, Dahlöf B, Lefkowitz M, Manfreda S, et al. Rationale and design of the avoiding cardiovascular events through combination therapy in patients living with systolic hypertension (ACCOMPLISH) trial: the first randomized controlled trial to compare the clinical outcome effects of first-line combination therapies in hypertension. Am J Hypertens. 2004;17(9):793-801.
88. Jamerson K, Weber MA, Bakris GL, Dahlöf B, Pitt B, Shi V, et al. ACCOMPLISH Trial Investigators. Benazepril plus amlodipine or hydrochlorothiazide for hypertension in high-risk patients. $N$ Engl $J$ Med. 2008;359(23):2417-28.

89. Chalmers J, MacMahon S. Perindopril protection against recurrent stroke study (PROGRESS): interpretation and implementation. J Hypertens. 2003; 21(Suppl.):S9-S14.

90. Chobanian AV, Bakris GL, Black HR, Cushman WC, Green LA, Izzo JL Jr, et al. National Heart, Lung, and Blood Institute Joint National Committee on Prevention, Detection, Evaluation, and Treatment of High Blood Pressure; National High Blood Pressure Education Program Coordinating Committee. The Seventh Report of the Joint National Committee on Prevention, Detection, Evaluation, and Treatment of High Blood Pressure: the JNC 7 report. JAMA. 2003;289(19): 2560-2572.

91. Mancia G, De Backer G, Dominiczak A, Cifkova R, Fagard R, Germano G, et al. 2007 Guidelines for the Management of Arterial Hypertension: The Task Force for the Management of Arterial Hypertension of the European Society of Hypertension (ESH) and of the European Society of Cardiology (ESC). J Hypertens. 2007;25(6): 1105-1187.

92. Sica DA. Rationale for fixed-dose combination in the treatment of hypertension: the cycle repeats. Drugs. 2002;62(3):443-462.

93. Staessen JA, Wang JG, Thijs L. Cardiovascular prevention and blood pressure reduction: a quantitative overview updated until 1 March 2003. J Hypertens. 2003;21(6):1055-1076.

94. Destro M, Luckow A, Samson M, Kandra A, Brunel P. Efficacy and safety of amlodipine/valsartan compared with amlodipine monotherapy in patients with stage 2 hypertension: a randomized, double-blind, multicenter study: the EX-EFFeCTS study. J Am Soc Hypertens. 2008;2:294-302.

95. Philipp T, Smith TR, Glazer R, Wernsing M, Yen J, Jin J, et al. Two multicenter, 8-week, randomized, double-blind, placebo-controlled, parallel-group studies evaluating the efficacy and tolerability of amlodipine and valsartan in combination and as monotherapy in adult patients with mild to moderate essential hypertension. Clin Ther. 2007;29(4):563-580.

96. Smith TR, Philipp T, Vaisse B, Bakris GL, Wernsing M, Yen J, et al. Amlodipine and valsartan combined and as monotherapy in stage 2, elderly, and black hypertensive patients: subgroup analyses of 2 randomized, placebo-controlled studies. J Clin Hypertens. 2007;9(5):355-364.

97. Poldermans D, Glazes R, Kargiannis S, Wernsing M, Kaczor J, Chiang YT, et al. Tolerability and blood pressure-lowering efficacy of the combination of amlodipine plus valsartan compared with lisinopril plus hydrochlorothiazide in adult patients with stage 2 hypertension. Clin Ther. 2007;29(2):279-289.

98. Brixner DI, Jackson KC 2nd, Sheng X, Nelson RE, Keskinaslan A. Assessment of adherence, persistence, and costs among valsartan and hydrochlorothiazide retrospective cohorts in free-and fixed-dose combinations. Curr Med Res Opin. 2008;24(9):2597-2607.
Vascular Health and Risk Management

\section{Publish your work in this journal}

Vascular Health and Risk Management is an international, peerreviewed journal of therapeutics and risk management, focusing on concise rapid reporting of clinical studies on the processes involved in the maintenance of vascular health; the monitoring, prevention and treatment of vascular disease and its sequelae; and the involvement of

\section{Dovepress}

metabolic disorders, particularly diabetes. This journal is indexed on PubMed Central and MedLine. The manuscript management system is completely online and includes a very quick and fair peer-review system, which is all easy to use. Visit http://www.dovepress.com/ testimonials.php to read real quotes from published authors. 